\title{
Twists and Turns: Splits, Snowballs and Tweaks in Cultural Theory
}

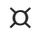

When colleagues of mine first learned of the conference "Re: Turns," on which this issue of eTopia is based, their almost unanimous response was to note how exciting and brilliant they found the theme. Some commented that they always felt called upon to write within a particular theoretical turn, rather than about it, and that the invitation to reflect on turns from a positon of temporary exteriority felt liberating. On the other hand, the challenge of writing about theoretical turns, I want to suggest, is that it requires that we disengage ourselves from some of the more pious ideas we might have about intellectual work. To think about turns is to admit that the agendas guiding our work do not simply arise through the appearance of political or cultural questions in the world. It is to acknowledge that, while the world poses questions to us all the time, these questions are given form within worlds of scholarship, which, at some very basic level, are like stock markets of rising and failing theoretical fashions

Turns are political in their own distinctive ways, but their political dimensions reside in the ways in which they organize intellectual work as a communal activity. This is distinct from seeing turns as one of the channels through which the world communicates, to us, its questions and urgencies. An attentiveness to turns may reveal something else, as well: that the state of theoretical thinking in a given moment is not usually the direct result of collective deliberation, as if everyone in a discipline or subfield were forever examining theoretical alternatives in order to agree upon those which seem most effective. Rather, we might usefully think of changes of theoretical perspective in the energetic terms of the cycle, as arcs of 
rising and declining attraction in which, to varying degrees, our work becomes imbricated. In this respect, the tests which theoretical positions confront are not only those of their adequacy, but those of their fashionability as well.

Of course, the fashionability of turns is what renders them so problematic. Fashionability suggests commodification, superficiality and transitory (and thus flimsy) commitments. To speak of theoretical turns as fashionable is to suggest that the surface dimensions of theoretical work - its style, its charisma - take precedence over its intellectual substance as the basis of judgement and adhesion. The fashionability of theoretical ideas is the sense they offer of pointing to a direction in which we want to go now, largely because we see so many others going there as well. How we interpret this collective movement - as the actions of a manipulated crowd or the ongoing transformation of community - will determine our judgement of fashionability.

What follows is organized as the posing of five questions about theoretical turns. The answers, of course, are partial and personal, offered here as the basis for further discussion.

\section{What are the politics of turns?}

As I was beginning to write the conference paper on which this article is based, the book Cultural Turns: New Orientations in the Study of Culture, by Doris BachmannMedick, appeared in English translation. Bachman-Medich astutely identifies what she calls the Janus-faced, double character of theoretical turns, a source of the discomfort we so often feel in talking about them. Turns are Janus-faced, Bachman-Medich suggests, because they represent the conflicting pressures to innovate and conform. More and more, she notes, "turn" is the name we give to theoretical renewal and innovation. Insofar as it suggests movement, "turn" implies progress and (despite the term's associations with deviation from a straight path) a forward movement. On the other hand, turns are the means by which intellectual life comes to be organized as a set of exhortations to conform. "After all," she writes, "[turns] function not only as drivers of innovation, but also as signposts that appear to point to the consensual pressures of research" (Bachman-Medick 2016: 8).

Let us leave aside, for a moment, the first half of these dualisms: the innovative dimension of turns. This, after all, is how we are happy to think about turns. The sticky, even uncomfortable side of theoretical turns has to do with the ways in which they enact what we might call collective shifts of attention. Significant numbers of people, in a theoretical turn, start to speak of the same things: of affect, for example, or materiality, or performativity. These collective shifts of attention are, at their most coercive, the results of what Bachmann-Medick calls conformative pressures: of a certain gentle policing of academic discourse. We might imagine these conformative pressures institutionalized in granting agency priorities or in the acceptance 
criteria used by journals or conference. In the early phases of a turn, these pressures work in less official ways. They are dispersed within the informal, even gossipy ways in which academics talk about the work of others. Conformative pressures are present in the ways we judge the works of others to be insufficiently up to date, or insufficiently bound to the momentum taking cultural theory in particular directions. While Bachmann-Medick speaks of these pressures as being conformative, she also, very soon thereafter, describes them as "consensual". And while consensus and conformity may both suggest forms of coercion, consensus offers at least a slightly more attractive image of collective behaviour.

Years ago, I wrote an article comparing the cultures of dance music to those of postGrunge alternative rock in the U.S. (Straw 1991). One of the arguments I wanted to make was that the field of dance music was organized around the dynamics of fashionability: that any sense of what was important was constantly changing, but that collective purpose in dance music culture manifest itself in a shared commitment to that change, to monitoring it and moving along with it. It was not as if, some day, dance music would land on the style or form which put an end to the need or desire for change. The commitment to change was the politics of the field, the basis of the communities which formed around dance music. The risk of giving oneself over to ongoing change was that you left, behind you, a long series of failed attempts at redirection, or a huge pile of ephemeral, non-enduring acts of musical expression. The joy of giving yourself over to ongoing change was that you were carried along in a process of collective experimentation in which consensus was constantly being sought and momentarily achieved. Within this cultural field, the constant remaking and redirecting of consensus, from something which was now to something else which came after it, was seen as a sign of collective health.

To invoke an example more germane to the focus of this article, I can remember a moment, perhaps twenty-five years ago, when it seemed that almost everyone I knew in cultural studies was reading Arjun Appadurai's anthology the Social Life of Things (Appadurai 1986). A couple of years ago, something similar happened with Jane Bennett's book Vibrant Matter (Bennett 2009). The pressure to read these things or risk being left out was gentle but it was, nevertheless, a conformative pressure. Colleagues of mine in non-English-speaking countries wrote asking me to send them copies of The Social Life of Things, quickly, since their colleagues seemed to have somehow acquired their own and kept mentioning it. Pressures we may see as rooted in competition for status also brought with them a collective focusing or refocusing of attention. In moments like this, scholars are asked to provide an account of their work in terms of theoretical turns in which those around them appear to be enlisting themselves. In the pressure, a couple of years ago, to situate one's own work in relation to Jane Bennett's Vibrant Matter, a certain policing was going on. This calling to account may have felt, to many, coercive and conformative, and I know people who resisted it as such. We might, nevertheless, see such moments of calling to account as slowing the dispersion of academic work 
into innumerable personal particularisms, as an insistence that at least part of our focus be shared.

The passage from Appadurai's The Social Life of Things to Jane Bennett's Vibrant Matter offers a useful example for more specific reasons, as well. The Social Life of Things was one moment in something called the "material turn". Some took this to mean, in more limited fashion, a "material culture" turn. They perhaps followed this turn on through the paths laid out by Bill Brown, in his conception of "thing theory" (Brown 2001), or through museum studies and collections studies, artefactoriented tendencies within memory studies and so on. The re-publishing, in 1993, of Susan Stewart's book On Longing, originally published in 1984, was clearly one effect of this turn (Stewart 1993). Jane Bennett's Vibrant Matter, on the other hand, came at a time in which the question of where the material turn might move next had already been posed for some time, and had offered up a number of alternatives. The more ambitious roads were those which detached material from "material culture", taking us into Object Oriented Ontologies, the post-human, materialist feminisms, Anthroposcene extinction theory and the sorts of ecologies Bennett herself proposed. Other, slightly more modest, strands within the material culture turn were reconfigured within media theory, platform theory, print culture studies and versions of actor network theory. Remnants of the old material turn are either being reconfigured within new turns, or left to simmer on disciplinary back burners.

We would all feel better, I think, if the form and substance of each theoretical turn were given to us by the non-academic world, - if each turn took its shape and purpose only from the political context in which it sought to intervene, and not from the internal dynamics of academic life. And yet, of course, this is never entirely the case. There are those who will believe Fredric Jameson, for whom the spatial turn in cultural analysis in the early 1980s was a response to a changed world: a world in which the experience of simultaneity and interconnectedness had replaced an experience of history (Jameson 1984). The spatial turn is partly that response, of course. But it was also a result of the playing out of paradigm shifts and theoretical fights within geography and anthropology reaching back to the 1960s, and of conflicts between these and other disciplines about who would lead the humanities and social sciences. Similarly, the astuteness of the articulation theory deployed by British cultural studies scholars in the early 1980s, in their analysis of Thatcherism, had much to do with a political situation which seemed to ask for a theory of articulation, in the face of a classical Marxism seemingly unable to do the job. But the elaboration of articulation theory was also an outcome of the long labour by which the Birmingham school worked its way through structuralism and linguistic theory and other French imports all through the 1970s, within a distinctive "theoretical" turn. 


\section{What other words have been used to describe theoretical change?}

I came into academic life at a time when there was scarcely any talk of turns. I mostly knew the term in one of its French versions, "virage," where it was used in political analysis to designate swings to the left or to the right; one spoke, for example, of the virage à droite of Mitterand's socialist party in France in the 1990s. If we revisit the language of theoretical change before we spoke of "turn", we find, of course, the language of the "post": of post-Marxism, post-Modernism, poststructuralism. The question lingered as to whether a period designated as "post" involved a negation and reversal of that which preceded it, or its absorption and further progress. Postmodernism might involve the reversal of various doctrines of modernism; post-structuralism, on the other hand, required that you hold on to several of the key breaks initiated by structuralism. Post-human is probably the most recent of posts, but it moves between a name for a particular kind of object and the name for a theoretical turn intended to transform the ways in which we deal with lots of objects.

Earlier, and in a way that now seems quaint but at the time was grandiose, people would use the word "age": the age of structuralism, the age of deconstruction and so on. The most current version of "age" is, of course, the anthroposcene, and, in the epic scale of the term, it is hard to imagine that others might succeed it. The history of cultural theory is dotted with various things called "new": the new historicism, the new cultural geography, neo-formalism in literary studies and so on. As Alysse Kushinski reminded us in her paper at the Intersections conference, a number of recent theoretical developments have been enlisted within the project of new feminist materialisms, which we may characterize as either a turn or a shift too large and enduring in its effects to be considered as such.

In Cultural Turns, Bachman-Meddick quotes Clifford Geertz's observation that, through much of the 1980s and 1990s, cultural theory did not live through turns so much as a series of wars: the science wars, the culture wars, the history wars (31). This is true, but the recognition of these wars needs to be tempered by two observations. One is that these wars were largely confined to the United States, and to a particular context marked first by Reaganism and then a general conservative ascendency. The second, related observation is that these wars were not so much theoretical turns as eruptions of academic work onto the terrain of public and publicly-funded culture. In this respect, then, they were of a different order than the "turn"; the question is not of whether or not such eruptions into public spheres transformed academic work, but of the modalities by which wars of this sort produce turns within theoretical work.

The term I would like to bring into the mix here is that of the "move". By move I mean something on a smaller scale, in its ambitions and effects, than a turn. For example, in literary theory, over the last 10-15 years, a variety of challenges have been mounted to the primacy of the act of reading in depth. Reading in depth was 
the activity of deconstruction: one pulled apart a text in order to reveal the contradictions buried within it; one rewrote a text to show that, whatever it thought it was about, it was really an allegory of its own failure.

Over the last twenty years or so, and mostly within literary theory, we've seen the floating of various alternatives to the practice of reading in depth. I designate this process as one of "floating" in the sense that stock operations are floated: suggestions are released into theoretical worlds and acquire momentum or quickly fade. Among the alternatives to "depth reading" we may point to neo-formalism (ex., Levinson, 2007); surface reading (Best and Marcus, 2009), the reparative reading which Heather Love (2010) offers as a remedy to the paranoid reading of desconstructionist practice, and the interest in minor and superficial aesthetic categories put forward recently by Sianne Ngai (2012). Briefly summarized, these interventions propose new formalisms which see textual forms as, basically, platforms, to be studied not for what is buried within or below them, but in terms of their schematic architectures; surface readings, which glorify the pleasures of the text which is lightly touched rather than immersed within; reparative and redemptive readings which, rather than digging deep to diagnose a text's failures, find within it the resources for hopefulness and affective reinforcement; and an attentiveness to what Sianne Ngai has called "minor taste concepts": the fleeting pleasures of the zany, cute and interesting, aesthetic categories typically neglected in a concern for the sublime and the beautiful.

What do we make of these innovations? We can locate them all, perhaps, within a larger transformation of literary studies, one based in a politics (largely feminist) of valorizing dimensions of experience excluded both from traditional and from deconstructionist literary theory. Bachman-Meddick would say that these larger transformations are too important and transversal to be labelled a turn. But the specific innovations listed here are perhaps, individually, too modest and contextual for anyone of them to initiate a turn. Perhaps, then, we need to speak of moves: the offering up of new tools or new objects which extend a range of possibilities or map out alternatives. We might ask of our own field, for example, whether the embracing of questions of infrastructure in media studies currently is the basis of a larger turn or a move within a broader (say materialist) turn.

\section{Is there a consensual history of theoretical turns?}

In preparing the talk on which this article is based, I read a great many histories of theoretical turns. There is a very simple version of this history, regularly repeated: that, in the beginning, there was the linguistic turn. And then, with the collapse or dissolution of the linguistic turn, there came the material turn. In this account, usually, the linguistic turn did its work, first, in cultural anthropology, with the recognition that knowledge, culture and the anthropologist's own accounts of their work were constructions of language. Karen Barad, for example, claimed in a 2003 
article, though to much dissension, that the linguistic, semiotic, interpretive and cultural turns are all about turning everything into language (2003; see also, for an account of the subsequent polemics, van der Tuin 2011). In many of these accounts, the material turn is offered as an anecdote to this imperialism of the linguistic and as occurring at a similarly large scale. If offered a clear alternative to the linguistic turn; it gave coherence to a whole series of ascendant concerns: with bodies, things, the natural world.

Histories of turns will vary in the extent to which they pay attention to institutional processes or the disciplinary politics of academic market forces. One of the questions to be asked is whether certain disciplines are better than others at initiating theoretical turns: either because they are endlessly conflicted, hothouses of theoretical innovation or because their prestige and power render them able to sell their turns to others. We may see anthropology as exemplifying the first of these conditions and English literature departments the second. Clive Barnett, a geographer, claimed once that cultural theory was literary theory on the move (Barnett 1998: 386). Most of the significant innovations across the cultural disciplines came, he suggested, when those disciplines read literary theory: when they read narratatology or structuralist analysis, or then read deconstructive readings, or when they came to literary theory's understanding of authorship as a construction, or of gender as performativity. At the same time, though, Barnett follows others in suggesting that the discipline which launched so many theoretical turns was geography. By going "cultural", he suggests, geography initiated the turn to space at the heart of so many turns. If literary theory, then, was the real source of so many of the ideas which fueled theoretical turns, cultural geography was the force that took them to market.

Barnet then suggests something else: that the spatial turn, from the 1980s onwards, fueled the growth of the cultural studies book market, and that the growth of this market augmented the prestige and influence of cultural geography (383-384). Further, he suggests that this market encouraged a high degree of personalization of academic work - that is, the marketing of academic work under the sign of the individual celebrity-author. In a back and forth, authors' names serve to anchor turns and give them solidity just as these works' own authority gathers weight from their being carried forward within a turn.

\section{What is the shape of a theoretical turn?}

On the first page of her book Cultural turns, Doris Bachman-Meddick offers an almost biblical genealogy of the process by which turns generate their successors:

The first groundbreaking steps in this direction - e.g., the interpretive turn, the performance turn and the reflexive turn - emerged in the field of cultural anthropology, but as the innovative disciplines switched, additional new focuses arose: the postcolonial turn, the translational turn, the spatial 
turn and the iconic/pictorial turn. These set the stage for a material turn, an affective turn, a social turn, a digital turn, an environmental turn and all the other theoretical turns that are still underway. (Bachman-Medick 2016: 1)

We might want to quibble with this sequence, which I think over-privileges the founding role of cultural anthropology. We might wonder as well, whether the spatial turn is really simultaneous with the iconic/pictorial turn, though the question is an intriguing one. We might wonder, as well, whether it is useful to speak of a "digital turn" rather than the subsuming of the digital within a variety of other turns. Let us think, though, of the forms that turns take here: that of a sequence of turns, each giving way to new sequences in models we might imagine as resembling branches of a tree (if the new turns are subsets of older ones) or like sets of train tracks (if each new turn is a new beginning).

A common but unacknowledged model of the turn is what we might call the "snowball". Here, a turn gathers up a series of moves or localized developments within a broader transformation of theoretical foundations. This is partly the image conveyed by Althanasiou, Hantzaroula, and Yannakopoulos, in their account of the "affective turn", which is taken to emerge from the gathering of "psychoanalytically informed theories of subjectivity and subjection, theories of the body and embodiment, poststructuralist feminist theory, conversation of Lacanian psychoanalytic theory with political theory and critical analysis, queer theorisation of melancholy and trauma" (Althanasiou, Hantzaroula and Yannakopoulos 2008). Similarly, Clive Barnett describes the constituent forces coming together to make the cultural turn as follows, as

a revivification of traditional areas of interest in cultural geography under the influence of new theoretical ideas; the "textualisation" of subfields such as political geography; the revival of interest in the historiography of geography under the influence of theories of colonial discourse and postcolonialism; a concern for the "cultural" embeddedness of economic processes; an interest in examining the mobilisation of culture as an accumulation strategy; a greater concern for examining relations between identity and consumption; an ever-greater sophistication in understandings of the construction of social relations of gender and race as well as class; a focus upon cultural constructions of environment and nature. (Barnett 1998: 380)

The presumption in the snowball model is that a certain transformation of quantity into quality occurs; the question is whether the constituent parts of a turn are themselves innovations, or whether they have been quietly doing their work for a long time, awaiting only that moment at which they are enlisted within something which looks like a turn.

There is also, within the history of turns, what I would call the tweak: when slight shifts in particular fields bring them into a larger phenomenon which may already be, or maybe will become, a turn: In management and public 
administration theory, for example, there are those who use cultural theory, invoking the work of Foucault on governmentality in order to develop ideas about the ways in which people manage themselves. In a localized disciplinary development, consideration of this concept of self-management has led to conceptualizing the state of shame as a factor in influencing behaviour. This interest in shame is named as the necessary convergence of management theory with affect theory: bits of academic work within management theory are now tweaked as contributors to a larger space of forward-moving theoretical momentum (Bjerg and Staunaes 2011). Similar tweaks, consensual or not, may be observed in fields which pass through turns while only occasionally exercising leadership within them. Here is Littau, a scholar of translation, describing a sequence of turns within her discipline: "Like other disciplines in the humanities, translation studies has undergone a number of "turns" since the 1970s: the "linguistic turn", the 'cultural turn' and the 'postcolonial turn', each overlapping with and feeding into the other. I want to suggest that translation studies is now undergoing a 'medial turn' (2011: 261).

\section{What are the geo-politics of turns?}

I would like to close with some brief remarks on the ways in which theoretical turns organize global relations of scholarly work and knowledge. Like the world of literature, the world of cultural theory is structured around what Pascal Casanova has called a "Greenwich Meridian", an invisible centre in relation to which other places are considered out-of-date or up-to-date (Casanova 1999). This produces the distinctive feeling, in particular parts of the world, of being perennially out of date, the sense that the value of local work has less to do with its contextual pertinence than with the possibility of its acceptance in the metropolitan centres of intellectual power.

I remember, a few years ago, people sharing a "pomo generator" via email and, later, social media. This digital gadget mocked the alleged styles of "postmodern" writing by producing phrases of obvious pretension and nonsense. Seemingly harmless, this gadget, as it circulated, generated anxieties among colleagues in other linguistic-national academic cultures for whom the project of engaging with theories of the postmodern still maintained a certain currency. At one level, it was a device for policing relations of up-to-dateness between those who got the joke and those for whom it arrived marked with the signs of cruel judgement. Less violent judgements of this theoretical dyssynchrony - because both sides occupy places of privilege within global economies of knowledge - are those by which French-language and English-language scholars of culture measure the currency of each other. In the quarter-century I have worked in a bilingual city, Francophone colleagues have expressed mystification at the engagement of English-language intellectuals with French theorists whose time they see as long 
past. This is particularly the case for figures like the sociologist Pierre Bourdieu, whom Anglophones may still employ as a radical alternative to English-language theories while those in the French speaking world know him principally through the weighty institutional power exercised by his disciples. More recently, as significant numbers of scholars in France have turned to the legacies of the Birmingham school, and of English-language cultural studies more generally, it is easy to snicker at an intellectual culture in which, for example, Laura Mulvey's "Visual and Narrative Cinema" was only translated into French in the 2010s.

Nevertheless, French scholars committed to rejuvenating their own media studies through ideas of the "active audience," or notions (long familiar to us) of articulation and conjuncture, are doing so in ways which, in their national contexts, are genuinely innovative and transformative. The long prior dismissal of these ideas (and the figures associated with them) in French academic worlds has made their invocation in the current moment a challenge to entrenched disciplinary orthodoxies, just as Deleuzian film theory partially dislodged the entrenched scaffolding of Anglo-American film theory in the 1990s and 2000s. Young cultural scholars in France and Quebec now speak of their interest in "les queer studies", "les gender studies" or "les fan studies", with the use of English terms signalling both their acknowledgement of the origins of these terms and their commitment to the political projects behind them. One can speak, even, of a "studies" turn across continental Europe. While, at one level, this signals the ascendant hegemony of English-language publishing companies and is thus, in Bachmann-Medick's terms, globally conformative, it is also, in its local instantiations, a significant force for innovation.

\section{References}

Athanasiou Athena, Pothiti Hantzaroula Pothiti and Yannakopoulos Kosta. 2008.

"Towards a New Epistemology: The 'Affective Turn". Historien, 2, 1-16.

Appadurai, Arjun, editor. 1986. The Social Life of Things. Commodities in cultural perspective. Cambridge, Cambridge University Press.

Bachman-Medick, Doris. 2016. Cultural Turns: New Orientations in the Study of Culture, translated from the German by Adam Blauhut. Berlin, Boston: de Gruyter.

Barad, Karen. 2003. "Posthumanist performativity: Toward an understanding of how matter comes to matter." Signs: Journal of Women in Culture and Society, 28(3), 801-831.

Barnet, Clive. 1998. "The cultural turn: fashion or progress in human geography." Antipode 30(4): 379-334.

Bennett, Jane. 2009. Vibrant Matter. Durham, North Caroline: Duke University Press.

Best, Stephen and Sharon Marcus. 2009. "Surface Reading: An Introduction." Representations 108(1): 1-21.

Bjerg, Helle and Dorthe Staunæs. 2011. "Self-management through shame - Uniting governmentality studies and the 'affective turn". Ephemera: theory E politics in organization 11(2): 138-156. 
Brown, Bill. 2001. “Thing Theory.” Critical Inquiry 28(1): 1-22.

Casanova, Pascale. 1999. La République mondiale des lettres. Paris: Seuil.

Jameson, Fredric. 1984. "Postmodernism, Or The Cultural Logic of Late Capitalism." New Left Review, 146, 59-92.

Levinson, Marjorie. 2007. "What is New Formalism?" PMLA 122(2): 558-569

Littau, Karin. 2011. "First steps towards a media history of translation". Translation Studies 4(3), 261-281.

Love, Heather. 2010. "Truth and consequences: on paranoid reading and reparative reading." Criticism 52(2): 235-241.

Ngai, Sianne. 2012. Our aesthetic categories: zany, cute, interesting. Cambridge, Mass.: Harvard University Press.

Stewart, Susan. 1993. On Longing: Narratives of the Miniature, the Gigantic, the Souvenir, the Collection. Durhan, North Caroline: Duke University Press. Originally published in 1984.

Straw, Will. 1991. "Systems of Articulation, Logics of Change: Scenes and Communities in Popular Music.” Cultural Studies, 5(3): 361-375.

van der Tuin, Iris. 2011. Review Essay: 'New Feminist Materialisms." Women's StudiesInternational Forum 34: 271-277. 